\title{
A Missing Link: Thinking | making | presenting
}

\author{
Zamila Karimi $^{1, *}$ and M Saleh Uddin ${ }^{1}$ \\ ${ }^{1}$ Kennesaw State University, GA USA
}

Keywords: Studio Teaching, Architectural Representation, Drawing, Design Thinking

\begin{abstract}
Let whoever may have attained to so much as to have the power of drawing know that he holds a great treasure ... Michelangelo

The tradition of architectural drawings and making as a means of design thinking in a constant feedback loop results in discoveries that facilitate creative thinking in an iterative process. In the digital age, notion of drawing and making by hand as a cognitive process of thinking is fading. This trend is increasingly evident in upper-level architecture students who depend strictly on digital tools for design thinking, missing many critical decisionmaking steps. Concepts of scale, diagramming, composition, materiality are missing - part of the challenge is the computer screen and the lack of tactical autonomy with physical materials - pen, pencil, brush, architectural scale, materiality, construction, assemblage. How can we as educators assert that drawings are not just architectural representations, but a means to architectural inquiry? Why is it critical for our students to use hand drawings, sketching and diagramming when exploring ideas? Can small gestural models provide notions of scale, materiality, and construction? Teaching pedagogy has always engaged new modes of design thinking and communications as a way of design inquiry - a trait essential to architects. Historically, since the Renaissance, drawings have been the catalyst to advance architectural discourse. In the $20^{\text {th }}$ century, different movements such as De Stijl, Constructivism and Bauhaus used a multi-disciplinary approach combining art and technology through the lens of drawing and making that led to a new wave of design pedagogy to push their imaginations into new territories which the digital augmented as technology advanced. We believe that today's students need to continue to develop both hand and digital skills in tandem to optimize design thinking, making and presentation techniques. In doing so, they can advance architectural pedagogy to new heights as those before did; critically in a material and physical sense: as an embodied spatial experience.
\end{abstract}

\footnotetext{
*zkarimi@kennesaw.edu : muddin3@kennesaw.edu
} 


\section{Introduction}

And it's always interesting, I think, to see how the future, or rather the forward-looking form of any discipline, always carries within it the seeds of its own triteness. William Gibson

The tradition of architectural drawings and making as a means of design thinking using handmind-eye coordination in a constant feedback loop results in discoveries that facilitate creative thinking in an iterative process. However, in the digital age, this notion of drawing and making by hand as a cognitive process of thinking is fading. This trend is increasingly evident in upper-level architecture students who depend strictly on digital tools for design thinking without employing their hand skills to think with critically missing many important decision-making steps. Notions of scale, diagramming, composition, materiality are acutely lacking - part of the challenge is the computer screen and the lack of tactical autonomy with physical materials - pen, pencil, brush, architecture scale, materiality, construction, assemblage.

How can we as educators assert that drawings are not just architectural representations, but a means to architectural inquiry? Why is it critical than for our students to use hand drawings, sketching and diagramming when exploring ideas? Can small gestural models by hand provide notions of scale, materiality, and construction?

\subsection{Pedagogy: Drawing as a mode of thinking}

Teaching pedagogy has always engaged new modes of design thinking and communications as a way of design inquiry - a trait essential to architects. Historically, since the Renaissance, drawings have been the catalyst to advance architectural discourse. In the $20^{\text {th }}$ century, different movements such as De Stijl, Constructivism and Bauhaus used a multi-disciplinary approach combining art and technology through the lens of drawing and making that led to a new wave of design pedagogy. Renewed interest in parallel projections/axonometry as a means of discovery and imagination was employed by both artists and architects to promote new vision of modernism. The impact of $20^{\text {th }}$-century avant-garde visualizing techniques was challenged by Russian Constructivist, which juxtaposed pure geometrical forms around a twisted frame as in Tatlin's monument of 1919 to announce a revolution in architecture. In the 1970s, these Constructivist drawings were explored by a group of rising architects at the Architectural Association in London as a means of design inquiry to find new meanings and relationships, Zaha Hadid's "The World (89 Degrees), 1984" is a critical commentary of the untested potential of Modernism through the lens of Russian Constructivist mode of drawings for a new lifestyle.

Even though modernism patronized straightforward and informative drawings, in many cases, the quality of architectural drawing stood out on those projects where getting the building constructed was not a serious consideration. While breaking away from the pragmatist tradition of the fifties, many new ideas became unveiled through visions for an architectural utopia. Archigram in England and the Metabolists in Japan and Vienna suggested a complete, attainable environment in their drawings rather than representing the structure to be built.

In the departure from modernism, the Post-Modern period introduced new intentions toward architectural drawing. Aldo Rossi in Milan, Oswald Mathis Ungers in Berlin, Raimund Abraham and Rob Krier in Vienna, and Leon Krier in London, all emphasized the relative independence of architectural drawing that led to a new aesthetic which eventually 
became recognized in its own right. Among American architects, Charles Moore, Michael Graves, John Hejduk, Robert Venturi, Steven Holl, and Peter Eisenmen are the pioneers. ${ }^{2}$

The MOMA "Deconstructivist Architecture" exhibition, curated by Philip Johnson and Mark Wigley (1988), featured drawings, models, paintings sketches of seven prominent contemporary architects-Frank Gehry, Daniel Libeskind, Rem Koolhaas, Peter Eisenman, Zaha Hadid, Coop Himmelblau, and Bernard Tschumi to showcase the revolutionary nature of their architectural drawings and models - even if it was on paper. These thinkers pushed the architectural discourse into new territories embracing digital technologies as is evident in the works of Frank Gehry, Zaha Hadid and the rest. This was a pivotal moment in history when "... the imaginative spirit of drawing ... continues to be instrumental to the development of the field." In retrospect, there is a common thread that runs amongst the thinkers who sketched, drafted and made models as a means to push their imaginations into new territories, which the digital augmented to catapult their careers. These thinkers were always in control of their craft like a true craftsman using both hand and digital in unison.

This type of criticality is lacking in today's emerging architects who use the digital not as a tool to think with but as a proxy to design with. There is a danger that comes with this dependency. They are as follows: a) lack of criticality in design thinking; b) spatial geometry and forms often is the result of some operations; c) notions of scale both figuratively and formerly is lost. The process is erratic and often missing many critical steps. Moreover, the iterative design process hand-mind-eye coordination in a constant feedback loop which often results in discoveries to facilitate creative thinking is compromised. Part of the challenge is the computer screen and the lack of tactical autonomy with physical materials - pen, pencil, brush, architecture scale, materiality, construction, assemblage.

Using student work from upper-level studios to illustrate the points, we will use three critical frameworks: a) Design thinking: an iterative process; b) Analog|Digital: a hybrid approach; c) Presentation Techniques to illustrate our hypothesis.

The lack of basic skills of drawing and making by hand as a cognitive process of thinking is fading amongst upper-level architecture students in the digital age. It is concerning to us as educators. We believe that our students need to continue to develop both hand and digital skills in tandem throughout their academic career thereby equipping them with proper skills to develop as critical thinkers.

\section{A Theoretical Approach}

I want to see things; I trust only this. I want to see, this is why I make drawings. I can see an image only if I draw it. ${ }^{4}$

Carlo Scarpa's profound statement about how an idea or an image comes to life and germinates when he physically draws is a concept that is foreign to today's students. Dependency on the computer as an all-knowing platform is a cause for grave alarm. Architecture is a complex multi-sensory tactical (haptic) phenomenon that requires hand/mind/making skills in a continuous loop as a cognitive process to generate ideas. Juhani Pallasma argues that "... the architecture of the eye detaches and controls, whereas haptic architecture engages and unites." ${ }^{5} \mathrm{We}$ as human encounter space via our seven senses: sight, hearing, taste, smell, touch, intuition, and equilibrium (body configuration/identification) as

\footnotetext{
${ }^{2}$ M. Uddin, Composite Drawing, Pg 4,5; McGraw-Hill, 1997

${ }^{3}$ A. Boyarsky, Drawing Ambience: Alvin Boyarsky and the Architectural Association http://www.kemperartmuseum.wustl.edu/exhibitions/9926

${ }^{4}$ F. Cocozza, Axonometry: The Grip of Thought on Space - A Short Survey on the Relation between the Act of Planning and a Visionary Visualization Technique. 2017

${ }^{5}$ J. Pallasmaa, Hapticity and Time: Notes on Fragile Architecture. 2000
} 
an embodied experience. The Vitruvian concept of architectural values: utilitas | firmitas | venustas is still as valid today as it was during the Classical period, which suggests that successful architecture achieves its goal of function, form, and delight in a seamless assemblage(s) through skillful crafting of space formally, functionally, and is a delight to be in. Thus, such an endeavor requires us to viscerally engage our primal faculties to augment architectural thinking at this moment in time of advanced 3D software and virtual reality screens, which often is a form of detachment from the spatial experience.

\subsection{Design thinking: an iterative process}

Computers tend to dematerialize design thinking and results in abstractions far removed from the world of human sensory experience... Perhaps we need to defer the use of computer as a tool for design inquiry in the beginning stages to avoid notions of dematerializtion and abstraction so as to generate ... a coherent design philosophy, good materials, craftsmanship and personal exploration. ${ }^{6}$

Diagramming and Sketching as a mode of visceral design inquiry using the innate capacities of the human brain for creative thinking ${ }^{7}$ in a constant feedback loop is missing in today's paperless studio environment. Research shows that for the brain to explore and incubate ideas one needs to be free flowing where physical, tactical gestures are activated critically to be imaginative and in a discovery mode to develop a design concept as a framework for an architectural project to germinate. During the design process, computers as design tools severely compromise the sense of scale, space, form, materiality as mere abstractions through a pixilated screen often lacking originality, which is a grave concern for us as educators. The sterile studio environment devoid of visual clues, hand sketches and physical threedimensional explorations, suggest lack of passion and excitement for studio projects. Students are often scared to commit to making sketches and models, as is the case with one thesis student who is convinced that she can design digitally. Refusal to make physical models and sketches in an iterative process has resulted in her design lacking any sort of part/framework for design. Program requirements for urban farming, which is highly dependent on physical site conditions, context, sun path, and topography, is not totally understood via a digital model. Even when she hesitantly built a site-model with diagrammatic sketches, she did not quite know how to use it in an iterative manner to push design thinking viscerally. Architect Jacob Brillhart attests that since architecture is a spatial experience, “... observation and experience, translated through drawing, inevitably informs design ... hand drawing accesses the \{intuitive \} right side of the brain ... builds a foundation for visual thinking." "Student dependency almost entirely on digital as a means of design exploration is a cause for alarm as it detaches the student from spatial and formal considerations. Digital platforms run the risk of limiting the student's investigations especially during the early stages of concept development, as the mind/hand needs to follow a rational approach of sequential thinking via the flat-screen lacking subtle nuances of the hand/mind gestural drawings thus limiting ideation. This trend continues in many practices where new generations of architects are at a loss in client meetings without their digital tools and revert to senior architects to rescue them. Many practices are offering sketching classes to new architects.

\footnotetext{
${ }^{6}$ H. F. Mallgrave, The Architect's Brain: Neuroscience, Creativity, and Architecture; 216, WileyBlackwell. 2011

${ }^{7}$ H. F. Mallgrave, The Architect's Brain: Neuroscience, Creativity, and Architecture; 214, WileyBlackwell. 2011

${ }^{8}$ J. Brillhart, Drawing Towards a More Creative Architecture: Mediating between the Digital and Analog.
} 


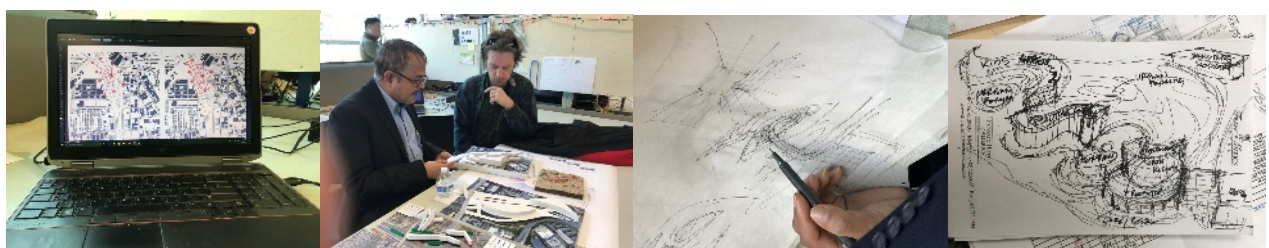

Figure 1. Desk Crits showing site on computer digitally prompting Professor to use hand sketches and physical materials to push design thinking tactically.

\subsection{Analog | Digital: a hybrid approach}

Modern brain scientists now know that your left brain is your verbal and rational brain; it thinks serially and reduces its thoughts to numbers, letters and words... Your right brain is your non-verbal and intuitive brain; it thinks in patterns or pictures composed of "whole things", and does not comprehend reductions, either numbers, letters or words. ${ }^{9}$

Historically, architects understood the idea of scale through hand-mind coordination via sketching and making on-site. The notion of light, shade, shadow, texture, materiality - had to be unraveled - rationalized and decoded to understand scale is all its dimensions. Relationships to the size of a reference object: human form or module of material formed the basis to understanding space with its three-dimensional form. However, that strategy gets compromised in today's pedagogical framework as digital tools get introduced to students at earlier levels. In such a context, some students find it difficult to leap between physical and digital models until a design is finalized. Students somehow believe that the sole use of digital will generate a thoughtful architectural outcome incorporating Pallasma's seven senses as spaces are organized compositionally.

Analog and digital forms of exploration have its own bias and a critical use of each media puts forward a mode of inquiry that enhances the design process. Neurological research shows that during the design development process an analog approach yields best results as the brain neurons and physical gestures tend to work together as an embodied experience to offer the most options/possibilities. Once the concept is achieved, then the digital mode of inquiry can be mobilized to now methodologically develop those concepts and ideas. The physical senses of the body - viscerally active - can never be replaced by the flat screen of the pixelated screen.

The notion of design thinking/making as a cognitive iterative process using both analog and digital in the current studio settings miss many critical steps thus compromising the outcome but more importantly highlighting deficiencies in our students. As students intersect/interweave the two platforms, there is utter confusion of rationalizing and making critical decisions in terms of scale, materiality, relationships, tectonics as they iterate site models and small diagrammatic design explorations, which require patience and commitment to the process in a methodological way. The data from google maps as a means of making physical models results in scalar confusions. Shifting scales between model space in digital drawings on 1 to 1 scale when juxtaposed onto a given site model scale with the physicality of material thickness or no thickness (foam) as contours lead to inaccurate physical models abstracted so drastically that their relationship to the existing context shows compromise. Mechanics of constructing with digital tools adds to the complexity of scale and relationships.

${ }^{9}$ H. F. Mallgrave, The Architect's Brain: Neuroscience, Creativity, and Architecture; 216, WileyBlackwell. 2011 

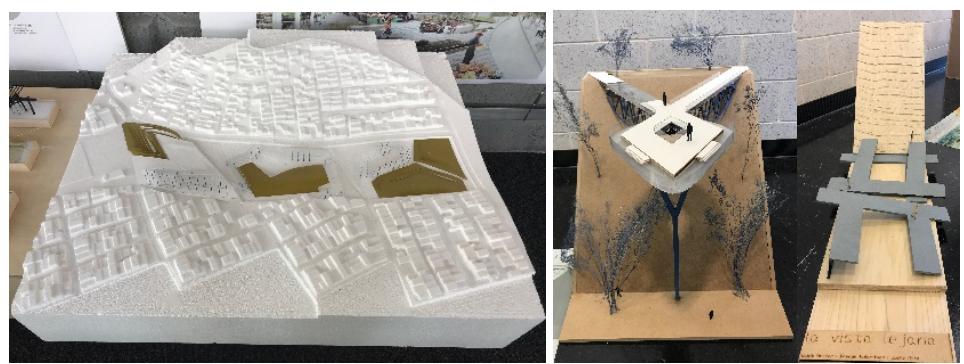

Figure 2. Site Models as caricatures for design exploration brings to question issues of scale | tools | materiality | relationships $\mid$ context
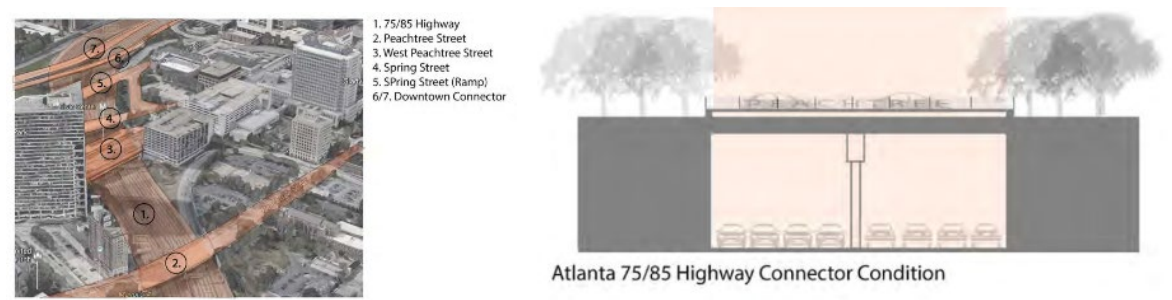

Figure 3. Site diagramming using digital tools allow students to record site conditions abstractly which may lead to wrong assumptions and readings thus requiring additional strategies to complete diagramming.

\subsection{Presentation Techniques: an opportunity}

Clearly no single design direction dominates today, and while it is possible to map shifting intellectual agendas, the situation is not so much that one agenda supplants another as it is that one is layered over another, multiplying the possibilities and points of view. ${ }^{10}$

Compositional strategy in the digital age is an architect's license to be successful both in the academics and in practice. Learning and succeeding in architecture schools requires design thinking skills to ideate with and compositional and presentation skills to organize and curate in a manner that is both informational and provocative. Design schools today are inundated with architectural presentations' that all look similar printed on same glossy paper and digital small-scale models resulting in homogenization. How can students creatively curate and compose their presentations to avoid such challenges? ${ }^{11}$ Studios traditionally have been a rite of passage to real-life practice where the students put their best effort forward both in terms of design intent and thought out presentation boards. However, today's students' dependency on digital tools as a primary driver of output may be an opportunity to rethink compositional strategies as a curatorial performance to optimize design thinking and presentation techniques. In doing so, today's students can advance architectural pedagogy to new heights as those before them such as Zaha Hadid, Frank Gehry, Thom Mayne.

\footnotetext{
${ }^{10}$ S. Allen, The Future that is Now, Places Journal, 2012

${ }^{11}$ H. F. Mallgrave, The Architect's Brain: Neuroscience, Creativity, and Architecture; 214, 215, Wiley-Blackwell. 2011
} 


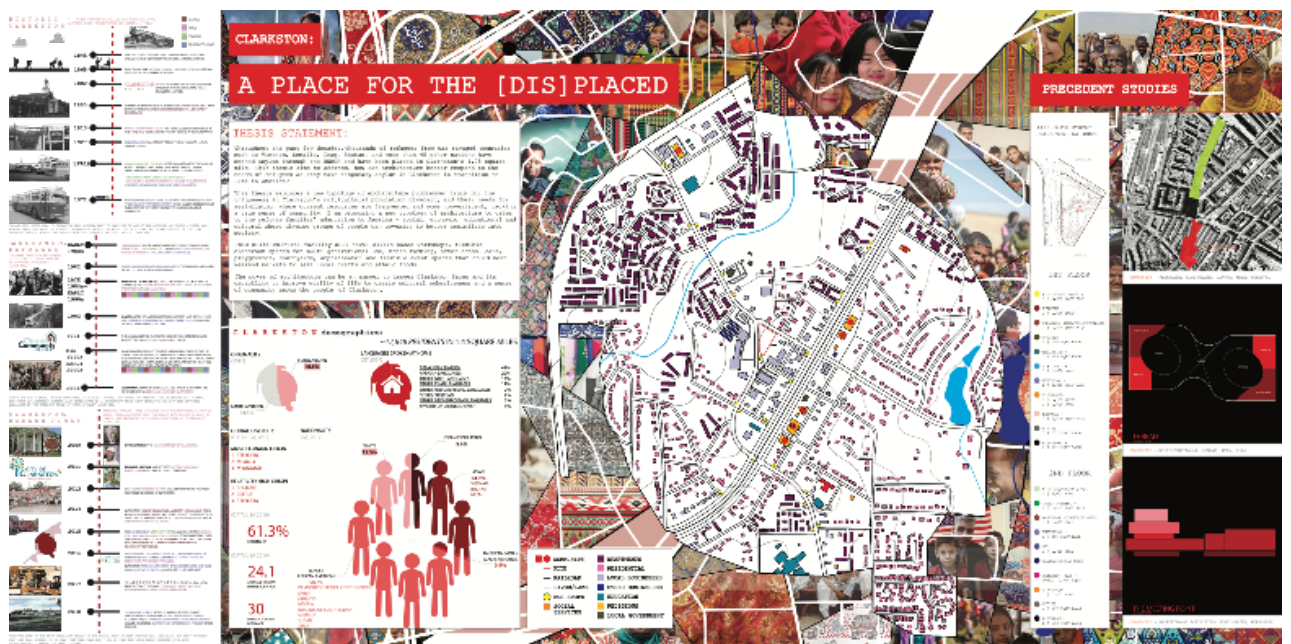

Fig 4. Posters cramming too much information lacking compositional cohesiveness: color, fonts, shapes resulting in boards hard to decipher.

\section{Conclusion}

The computer is an important tool - no one could do without it - but for me it's a tool and it doesn't replace thinking. It can make you disconnected and autistic, and that is why we always say, bring it out of the computer, print it up, use paper, use the physicality's and models to understand and anticipate what this thing will be in the end: something physical, something real, something for the people... Pierre de Meuron ${ }^{12}$

We as educators do not deny the importance of analog and digital to work in a complementary relationship to advance design inquiry responsibly so as not to compromise on the Vitruvian values of utilitas | firmitas | venustas and Pallasma's seven senses for a rich spatial experience. With the rise of digital technologies, we as architects must never give up our critical thinking skills of questioning and problem solving in a material and physical sense: as an embodied spatial experience. While we excitedly adopt and adapt digital tools to advance architectural pedagogy, it all begins with the brain to draw upon all its specialized areas and potential strengths to foster creativity. ${ }^{13}$ To explore and incubate ideas one needs to be free flowing where physical, tactical gestures are activated critically to be imaginative and in a discovery mode to develop a design concept as a framework for an architectural project to germinate.

\section{References}

1. A. Boyarsky, Drawing Ambience: Alvin Boyarsky and the Architectural Association http://www.kemperartmuseum.wustl.edu/exhibitions/9926

2. F. Cocozza, Axonometry: The Grip of Thought on Space - A Short Survey on the Relation between the Act of Planning and a Visionary Visualization Technique. 2017

\footnotetext{
${ }^{12}$ H. F. Mallgrave, The Architect's Brain: Neuroscience, Creativity, and Architecture; 220, WileyBlackwell. 2011

${ }^{13}$ H. F. Mallgrave, The Architect's Brain: Neuroscience, Creativity, and Architecture; 220, WileyBlackwell. 2011
} 
3. H. F. Mallgrave, The Architect's Brain: Neuroscience, Creativity, and Architecture; 216, Wiley-Blackwell. 2011

4. J. Brillhart, Drawing Towards a More Creative Architecture: Mediating between the Digital and Analog.

5. J. Pallasmaa, Hapticity and Time: Notes on Fragile Architecture. 2000

6. M. Uddin, Composite Drawing, Pg 4,5; McGraw-Hill, 1997

7. S. Allen, The Future that is Now, Places Journal, 2012 